\title{
From Detail to Project: House Cajozzo-Facciolà
}

\author{
Manuela Milone
}

\section{Abstract}

The analysis and understanding, through drawing, of Casa Cajozzo-Facciolà, designed by Pasquale Culotta and Giuseppe Leone, in 1979, on a cliff in Contrada Ogliastrillo in Cefalù, followed a process that is unlike the traditional process. From the consideration that the detail is thought of as a portion of a whole, which allows, through a close examination, to re-read the global system from which it was provisionally extracted, we proceeded with the analysis of the expected construction system, the balloon frame, and thanks to a close examination of the construction details of which there were sketches with explanatory notes, the proportions, spaces, volumes, surface treatment of the overall design were interpreted, defining their language. Useful for the constructive interpretation process was being able to interface with some US projects, a clear reference for designers. From the construction system to the technological detail, it was possible to proceed to a 2D model in the first instance and then a 3D model, for a reinterpretation of the entire project, also in its urban setting, to understand its meaning in the complex design and cultural process that they have moved the facies of the work.

Keywords

detail, redesign, balloon frame, Cefalù, graphic representation.

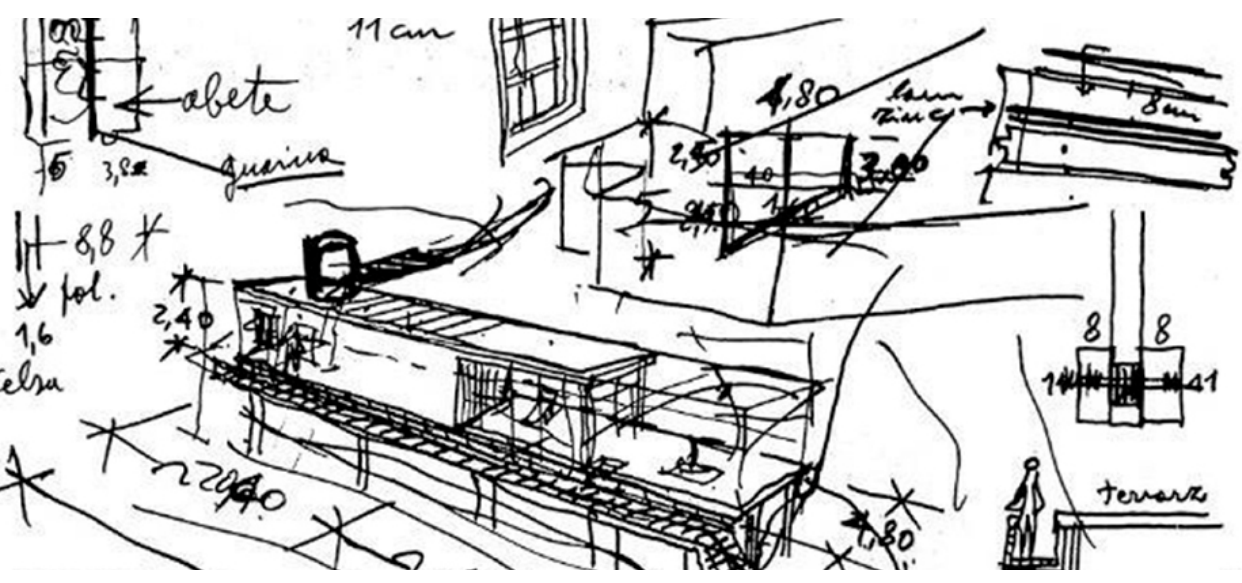


Before describing the analysis made on Casa Cajozzo-Facciolà, designed by architects Pasquale Culotta and Giuseppe Leone, let's introduce the concept of detail in architecture. The detail is conceived as a portion of a whole, which allows, through a close examination, to re-read the global system from which it was provisionally extracted. The detail represents our main system and comparison tool. The details of the construction details provide some information, and some rules must be used which are especially useful in making the various levels of design connected and complementary to each other. The detailed sketches allow us to interpret the proportions, spaces, volumes, surface treatment of the overall design by defining its language. The reading of some drawings teaches us how certain effects have been achieved, how certain functional and constructive needs are resolved, how the detail characterizes the complex and how the complex in turn takes effect from certain elements of detail. Culotta and Leone's first trip to America takes place in 1978 and will bring news and ideas to their projects from the living traditions of those places they visited. In the case of the Casa Cajozzo-Facciolà project, the architecture that fascinated the two Sicilian architects, to which they refer, is the planned coastal community of the Sea Ranch, in Sonoma County on the Pacific coast, born thanks to the architect's ideas Alfred Anton Boeke, the designer and landscape architect Lawrence Halprin, the architects Joseph Eshericke and the MLTW group, which can be considered a social, architectural and environmental experiment: a series of residences capable of mediating between the indispensable tradition of the single-family home and the idea of community. Here, the structures and curtain walls, strictly in wood, evoke the construction tradition of the "balloon frame", and the references are clearly of vernacular roots. Thanks to the contribution of the landscape architect Lawrence Halprin, the local ecology was taken into account. Halprin in fact studied the natural conditions of the place to adapt the urbanization proposal to the specific place in the best way.
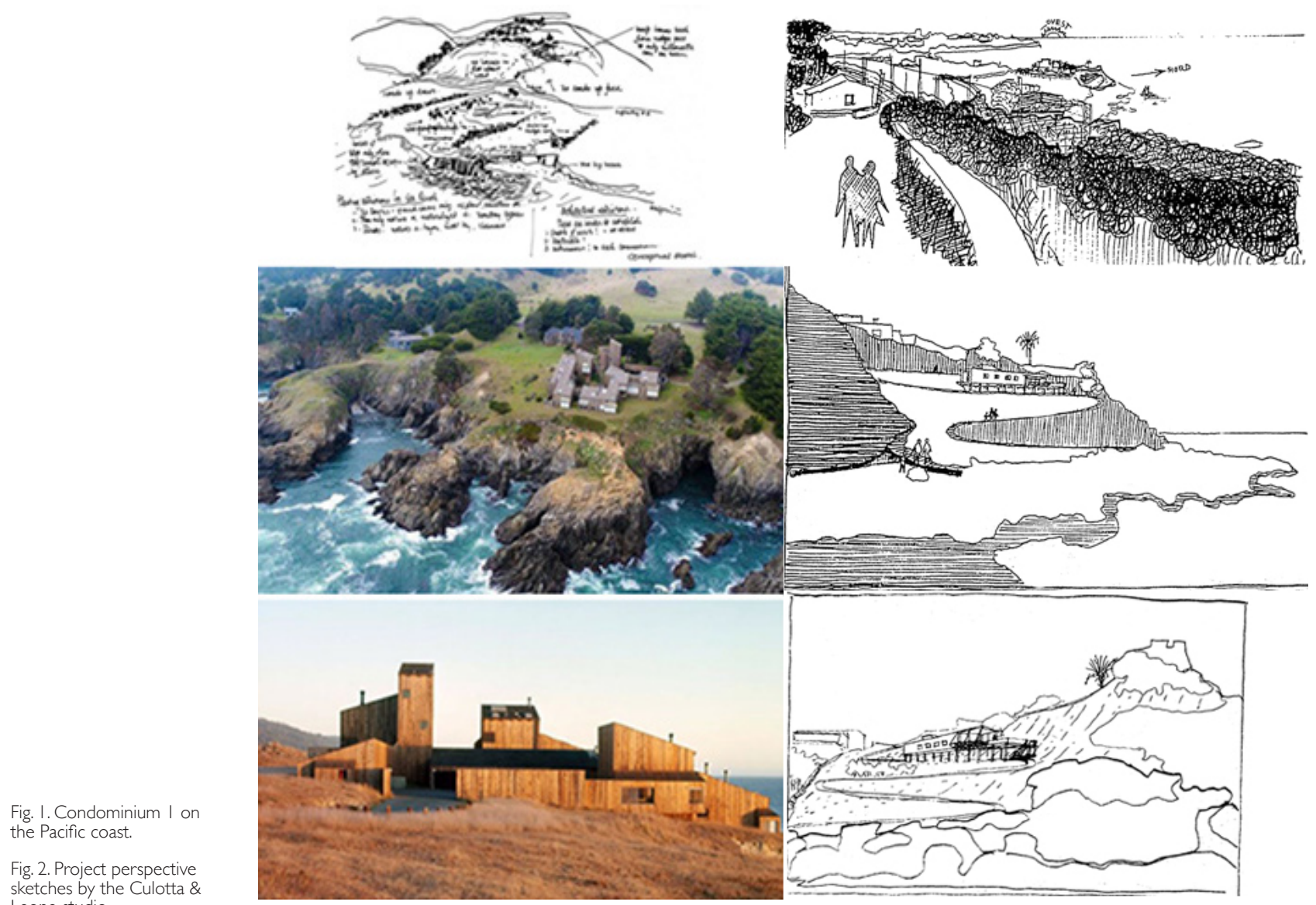
A good planning of the site has taken into account its main geomorphological, climatic, hydrographic, botanical characteristics, etc. (fig. I).

Similar is the project site of the Cajozzo-Facciolà house, traced thanks to some perspective sketches: a small promontory just over 10 meters high, on the coast of Cefalù, on which there is what was probably an ancient lookout point (fig. 2).

Starting from a limitation of the zoning plan legislation that established non-permanent buildings in wood or similar material for the area, the project for the Cajozzo-Facciolà, is conceived as a linear building, with longitudinal plant, single material and built according to the construction technologies of wooden houses. Here, too, the inevitable paths consisting of ramps, stairways and resting places connect the various levels, weaving a web of relationships 'inside and outside' the organism: from the road they reach the house, cross it and flank it, then descending to the sea. The building, located on the north-east side of the low promontory, has an upstream face which is the most reserved one, where a path adapting to the difference in height of the cliff leads to the entrance, which, like the entrance to a refuge, is excavated. inside the volume of the house. The idea of a refuge or an outpost to shelter and safely dominate the wilderness scene returns here, and at the same time the reference is also to the idea of the ship. The view is projected onto the sea and the horizon, visible through the large windows that lead outside from the dining room to a terrace that resembles the foredeck of a ship.

This open space, together with the volume of the house, is raised from the reinforced concrete base. from a series of wooden pilotis, which on the main front mark 12 spans. The main front is the one facing north-east on which all the rooms of the house overlook, therefore on the seaside, through a window. The terrace overlooking the sea can also be reached by following the path above, which leads from the back to the entrance, and which, flanking the volume of the house, reaches this open space, via a vertical connection, to reach the footfall level of the house. single floor of this house. The walkway continues and descends towards the sea via another flight of stairs, located at the end of the terrace, which descends from the height of the house to another path which then winds towards the expanse of water. The north-east face rises from the cliff for 6.50 meters: 2 meters of these are the wooden pilotis that raise the volume of the house. The mountain side front,
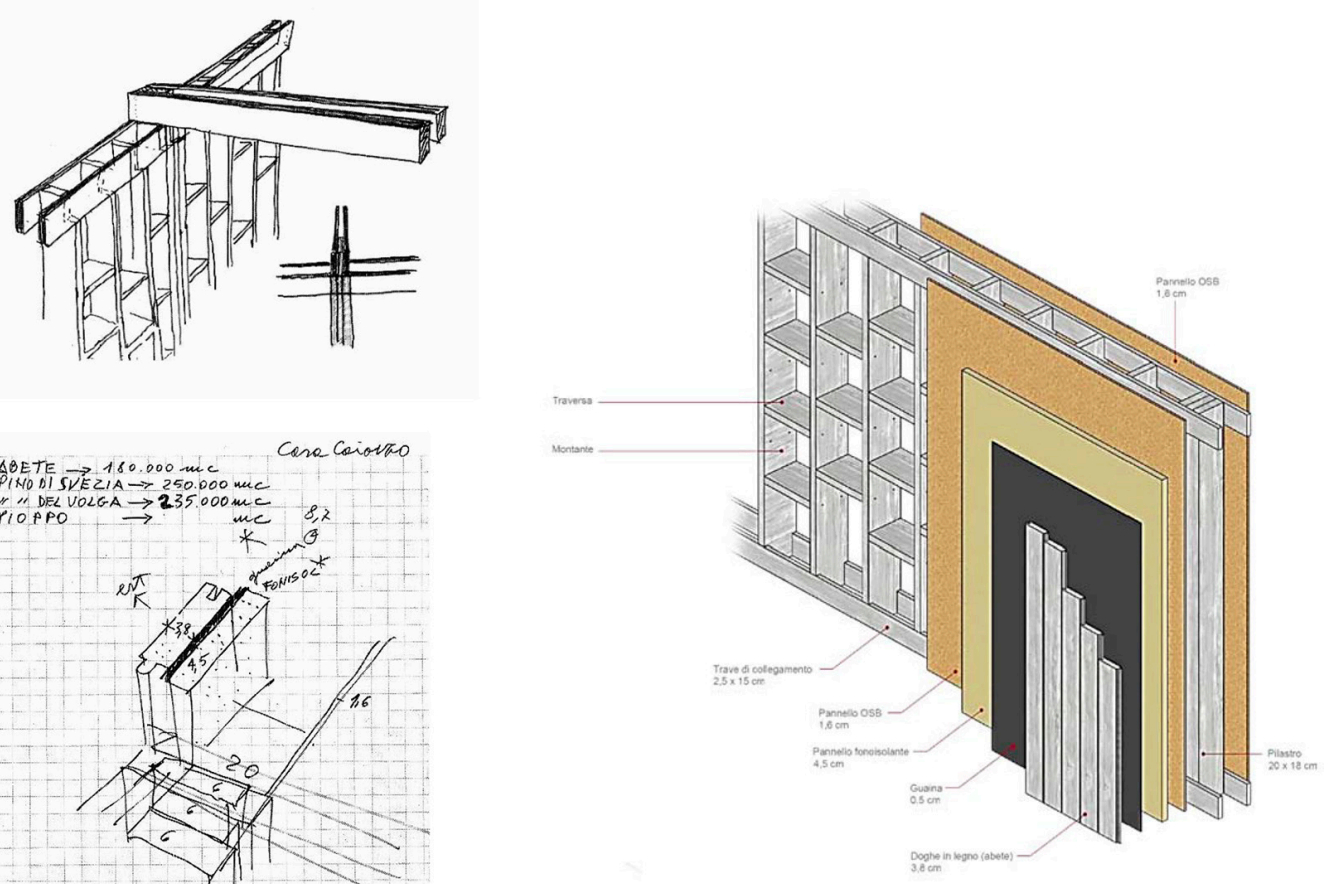
on the other hand, is high, only 1.5 meters. The single-pitched roof that descends towards the mountain, upon arrival from the rear, is therefore clearly visible as a fifth facade. From this pitch the volume of the skylight rises, in the direction of the internal corridor, the latter covered by a narrow pitch inclined towards the sea.

To analyze and better understand the construction system that gave shape to the project, it was appropriate to briefly review the origin of the wooden construction systems, in this case the balloon frame and its evolution in the platform frame.

The birth of the first mechanized sawmills and the industrial production of nails allowed the creation of a lighter supporting structure than the previous ones: uprights and transoms, of reduced section, very close together and braced to absorb and counteract the horizontal thrusts, form the frame of the house; the whole is finally covered with boards nailed or fixed with wooden pins to the frame. This first construction system, with a wooden frame, is the balloon frame, typical of American cottages. In this system, the uprights can have a maximum height of two floors, without interruptions from the ground to the roof. This system provided that uprights and rafters were placed at a distance such as to be able to eliminate the heavy framed beams and also avoid joints and notches thanks to the nailing. By nailing a board halfway up to the uprights, it was possible not only to support the load of the roof but also to build the upper floor.The beams are fixed to the side of the uprights by nailing, while an upper rail supports the roof frame. As an evolution of the balloon frame, the platform frame construction method was developed, which made it possible to exceed the maximum height of two floors, making it possible to build buildings up to six floors high. In the platform system, the pillars are interrupted by the attic of the first floor and each subsequent floor, built independently, rests on the lower one that acts as a platform, hence its name. The platform frame is a lightweight construction method that has the possibility of being built directly on site or pre-assembled in the factory complete with fixtures and insulation, for a quick installation that will consist in placing the walls together and overlapping the horizontal frames of the floors.

In Casa Cajozzo-Facciolà the architects Culotta and Leone describe the construction system they had thought of: modulated by a double framework, main and secondary structure, in wooden planking, anchored to the laying surface by means of steel glasses bolted to the reinforced concrete foundation. The textures of the roof and the floor slab are in cross laminated wood linked to the piers and beams through steel brackets and bolts.

The pillars $(20 \mathrm{~cm} \times 18 \mathrm{~cm})$ arranged in the direction of longitude, at a distance of $2.50 \mathrm{~m}$, are anchored to the laying surface by means of steel cups bolted to the reinforced concre-
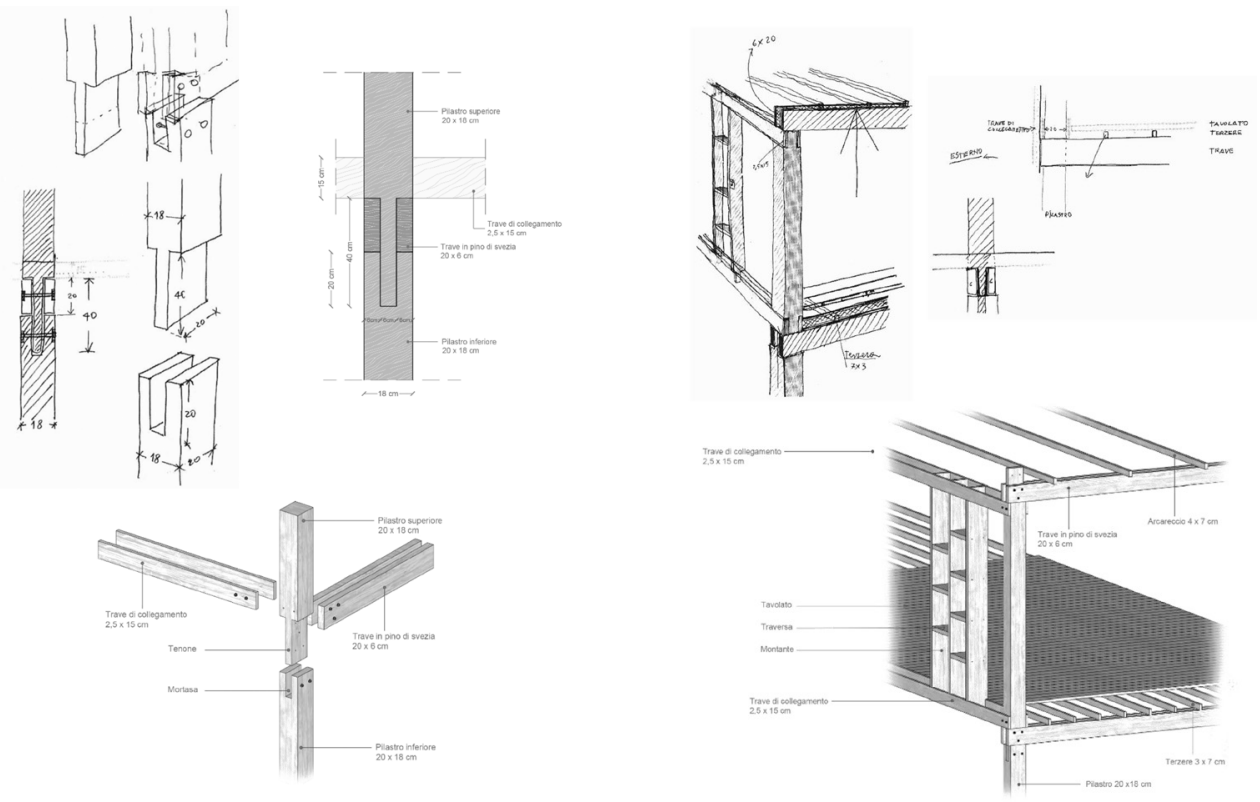
te foundation. The wooden frame construction system used here is the already described "balloon frame". This framed system has a plate operation: walls, floors, uprights and other components form box-like frames, and the vertical and horizontal loads of wind and earthquake are discharged to the foundations. The traditional diagonal bracing at the corners of the building, in the case of the Cajozzo-Facciolà house, are replaced by $1.6 \mathrm{~cm}$ thick OSB (Oriented structural board) sheets, nailed along the entire length of the wall, both inside and on the external face where other layers are applied: the soundproofing panel $(4.5 \mathrm{~cm})$, the sheath $(0.5 \mathrm{~cm})$ and finally the cladding slats $(3.8 \mathrm{~cm})$, provided in fir wood and interlocking, in a vertical position. This package then covers the frame of the internal structure of the wall, formed by uprights and crosspieces joined by pinning and arranged between the pillars (fig. 3). Each pillar is composed of segments connected to each other: the lower pillar, which goes from the base to the first level, connects with the upper pillar through a type of interlocking connection, called tenon and mortise, consisting of a male (tenon) and from the corresponding housing (mortise) (fig. 4).

The beams are also placed at the height of these joints, using a triple node system. The main beams $(2 \times 20 \mathrm{~cm} \times 6 \mathrm{~cm})$ are grafted laterally to the pillar, exactly to the tenon $(6 \mathrm{~cm}$ thick). The tenon is $40 \mathrm{~cm}$ long: for $20 \mathrm{~cm}$ it accommodates the double beam, which is joined by $6 \mathrm{~cm}$ on one side and $6 \mathrm{~cm}$ on the other, and for the other $20 \mathrm{~cm}$ it fits into the mortise. The connecting beams $(2.5 \mathrm{~cm} \times 15 \mathrm{~cm})$, which support the frame of the external walls and to which the cladding is also hooked, are bolted laterally to the pillar (on the internal and external faces) (fig. 5).

The main beams support rafters $(3 \mathrm{~cm} \times 7 \mathrm{~cm})$ and the floor planking on the first level. In the roofing system, the main beams, on the other hand, support: the purlins $(4 \mathrm{~cm} \times 7$ $\mathrm{cm}$ ), Swedish pine boards, a layer of bitumen sheath and the corrugated sheet in galvanized steel; the latter collects the rainwater in the hidden eaves, together with the deck system just described, inside an attic, covered by a single sloping pitch, where on the inclined beams rest additional purlins that support the planks of final covering $(17 \mathrm{~cm} \times 3.8 \mathrm{~cm})$, also in Swedish pine, soaked in bitumen and spaced $2.5 \mathrm{~cm}$ apart for the flow of rainwater in the
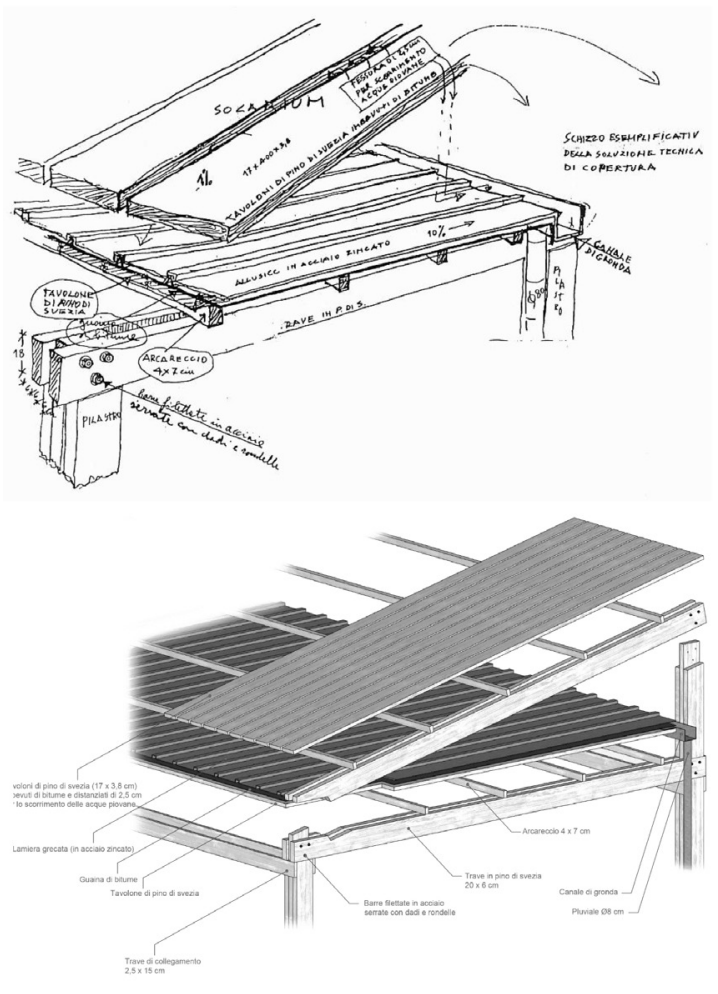
technical volume below. This system of covering and collecting rainwater therefore allows natural ventilation within what we can think of as a 'ventilation chamber' of a ventilated roof, reducing the heat in the summer and allowing the disposal of water vapor during the winter (fig. 6).

In the next phase, the model obtained was imported into the Autodesk 3ds Max software with which, after setting the Corona Renderer as the rendering engine, materials were applied, the sun (Corona Sun) and the sky (Corona Sky) as light sources, to finally arrive at a more or less realistic effect. It has been hypothesized, considering that Casa Cajozzo-Facciolà was never built and therefore in the absence of real executives or a technical report, a monochromatic model with a single white wooden material with the exception of the glass and some metal parts. After positioning cameras (CoronaCam) to capture views of the model oriented according to the photos of the site obtained with the drone, high quality renderings were produced, subsequently inserted thanks to photo-matching (technique used to insert a rendering in a photograph, realistically positioning the model in the context of the planned site) on the site where Casa Cajozzo-Facciolà was to be built. Through the Adobe Photoshop CC software we then moved on to the post-production of these photo insertions that allow us to have an idea of what the two architects had imagined and designed (fig. 9).

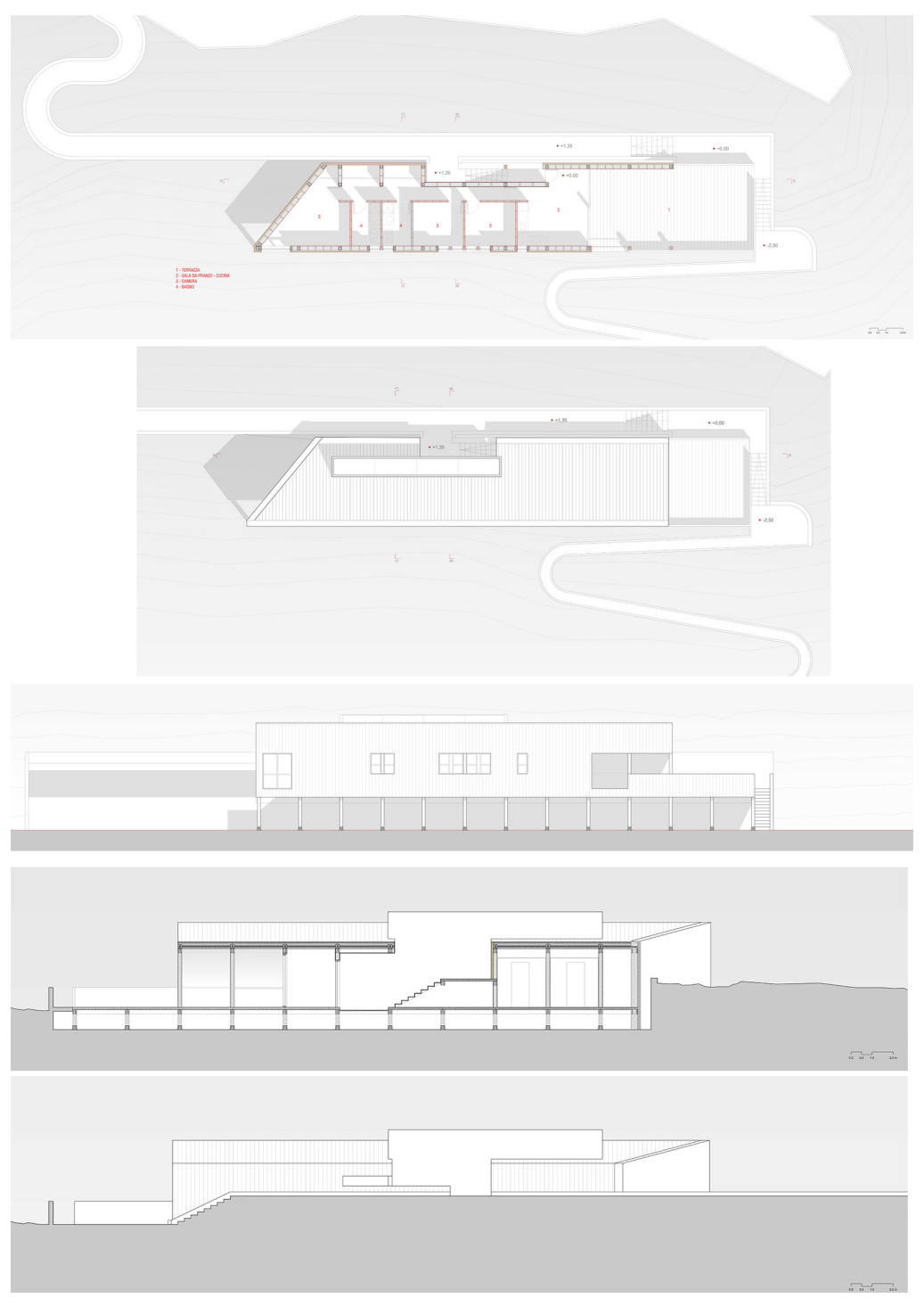



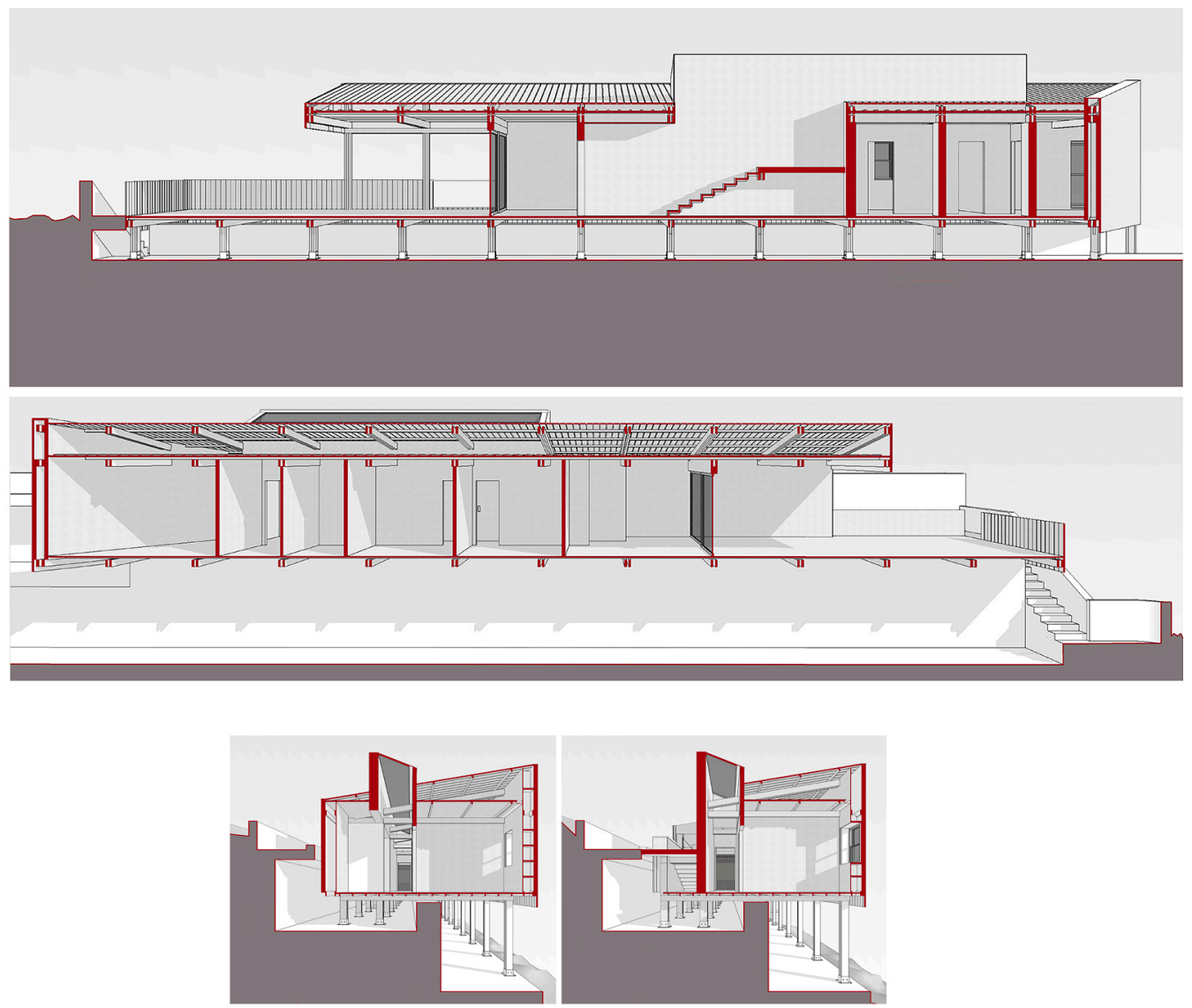

The design opened up to various possible themes, from technology to urban planning, this allowed us to understand what lies behind an architectural project. Casa Cajozzo-Facciolà, from what emerged during this journey, stands on the shores of the Mediterranean recalling the volumes that Moore, Lyndon, Turnbull and Whitaker had on the Pacific coast; and the two masters, as in their other projects, have proposed a synthesis of several traditions and ways of thinking about architecture. Here, too, the domination of architecture inserted in the vastness of nature was striking. An architecture that seeks integration and acts as an intermediary between man and place. The Sea Ranch urbanization study was a clear example of how architects design not only living spaces, but ways of living. A cliff comes to life and offers those who live there a unique way of life; living suspended over the expanse of the sea, like on a traveling ship. Analyzing this project it emerged how the place becomes the dimension of the project.

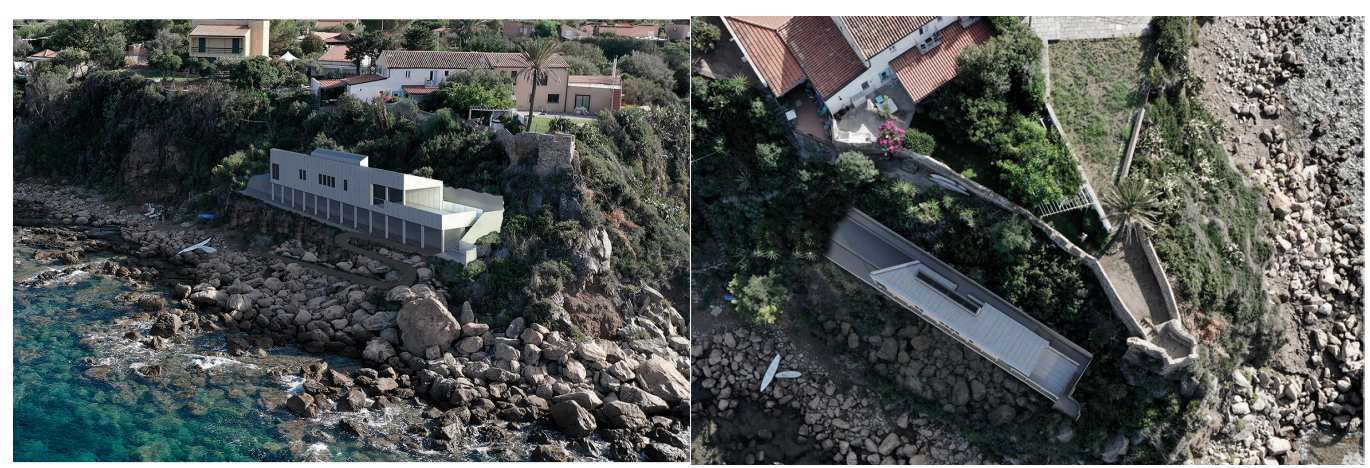




\section{References}

AA.VV. (20 I2). E. Journal. Palermo architecture - $n^{\circ}$ । I, July. Palermo: UAM-Productions

AA.V. (20 I2). E. Journal. Palermo architecture - n I2, July. Palermo: UAM-Productions.

Bacigalupi V., Benedetti C. (199I). Wood architecture - The future of tradition. Roma: Edizioni Kappa.

Culotta P., Leone G. (1985). The opportunities of the project. Cefalù: Edizioni della Medina.

Giordano G. (1964). The modern technique of wooden constructions - atlas. Milano: Hoepli.

Johnson E.J. (1986). Charles Moore buildings and projects, 1949-1 986. Milano: Rizzoli.

Moore C. (2000). The place of houses. Berkeley: University of California Press.

Mottura G. (2012). Building with laminated wood. Santarcangelo di Romagna: Maggioli.

Panzarella M. (2013). Culotta and Leone in Cefalù. Single-family houses. Geraci Siculo: Edizioni Arianna.

Sciascia A. (2013). "Architecture and phenomenology in Palermo". In Palazzotto E. (ed.). Experiences in the restoration of the modern. Milano: FrancoAngeli.

\section{Author}

Manuela Milone, Università di Palermo, manuela.milone@unipa.it

To cite this chapter: Milone Manuela (2021). From detail to project: House Cajozzo-Facciolà. In Arena A., Arena M., Mediati D., Raffa P. (a cura di). Connettere. Un disegno per annodare e tessere. Linguaggi Distanze Tecnologie. Atti del $42^{\circ}$ Convegno Internazionale dei Docenti delle Discipline della Rappresentazione/Connecting. Drawing for weaving relationship. Languages Distances Technologies. Proceedings of the $42^{\text {th }}$ International Conference of Representation Disciplines Teachers. Milano: FrancoAngeli, pp. 90 I-908. 